\title{
SEGMENTASI KONSUMEN COFFEE SHOP GENERASI Z DI JATINANGOR
}

\section{SEGMENTATION OF COFFEE SHOP'S GENERATION Z CONSUMERS IN JATINANGOR}

\author{
Diana Rachmatunnissa*, Yosini Deliana \\ Program Studi Agribisnis Fakultas Pertanian Universitas Padjadjaran \\ Jalan Raya Jatinangor Sumedang Km. 21 \\ *E-mail: dianarachmatunnissa@gmail.com \\ (Diterima 17-09-2019; Disetujui 12-11-2019)
}

\begin{abstract}
ABSTRAK
Tingkat konsumsi kopi di Indonesia semenjak tahun 2013 selalu mengalami peningkatan. Hal ini seiring dengan meningkatnya jumlah coffee shop yang bermunculan di berbagai daerah di Indonesia. Selain sebagai tempat membeli dan mengkonsumsi kopi, coffee shop telah mengembangkan fasilitasnya agar konsumen dapat menghabiskan waktunya di coffe shop untuk bersosialisasi atau sebagai tempat tenang untuk mengerjakan tugas. Dengan perkembangan ragam fasilitas coffee shop juga terjadi perkembangan pola pikir konsumen. Pada beberapa tahun terakhir ini, generasi $\mathrm{Z}$ mulai berkembang dan menjadi salah satu target demografi konsumen coffee shop. Lingkungan Kecamatan Jatinangor merupakan kawasan pendidikan yang menjadi tempat aktivitas para mahasiswa yang umumnya termasuk ke dalam generasi $Z$. Tujuan penelitian ini yaitu untuk mengetahui karakteristik konsumen generasi $\mathrm{Z}$ dan untuk mengidentifikasi preferensi coffee shop bagi generasi $\mathrm{Z}$ di Jatinangor. Pemilihan sampel dalam penelitian ini menggunakan systematic random sampling dengan sampel sebanyak 163 responden. Analisis yang digunakan adalah analisis deskriptif dan analisis diskriminan. Hasil penelitian menunjukkan karakteristik demografis dan psikografis konsumen coffee shop besar dan coffee shop kecil generasi Z di Jatinangor dan menunjukkan terdapat perbedaan yang signifikan pada variabel usia, intensitas, biaya, rata-rata kunjungan, jumlah orang, jarak, waktu tempuh, waktu di coffee shop, dan jam berkunjung pada kedua kategori coffee shop.
\end{abstract}

Kata kunci: preferensi konsumen, generasi Z, analisis deskriptif, analisis diskriminan

\begin{abstract}
Coffee consumption rate in Indonesia has been increasing since 2013. This fact goes simultaneously with the increase of the number of coffee shops that was built in the last few years. Aside from being a place in which consumers can buy and consume coffee, these coffee shops also developed theirs facilities so that it can be a place for the consumers to socialize or as a comfortable place to do their works. Along with the development of the coffee shops' facilities, there is also a development in the consumers' mindset. In the last few years, generation Z has began to grow and became one of the targets of coffee shop consumer demographics. Jatinangor is an education area where a lot of students, who are included as generation $Z$, do most of their activities. The purpose of this study is to identify the characteristics of generation $Z$ consumers and to identify the preferences of generation $Z$ consumers towards coffee shops in Jatinangor. The sample selection in this study used systematic random sampling technique with a sample of 163 respondents. The analysis used was descriptive analysis and discriminant analysis. The results of this study showed the demography and psychography characteristics of generation Z consumers in a big coffee shop and a small coffee shop in Jatinangor and showed significant differences in variables such as age, consumption intensity, expense, number of visits, number of people, distance, traveling time, time spent at the coffee shop, and visiting time between the consumers.
\end{abstract}

Keywords: consumers' preferences, generation Z, descriptive analysis, discriminant analysis 


\section{PENDAHULUAN}

Kopi merupakan komoditas perkebunan yang memiliki banyak peminat di Indonesia. Dalam beberapa waktu terakhir, minat masyarakat terhadap kopi semakin meningkat. Dalam statistik mengenai konsumsi kopi dunia, International Coffee Organization (2018) mencatat bahwa konsumsi kopi masyarakat Indonesia terus meningkat selama tahun 2013-2017 dengan peningkatan sebanyak $3.4 \%$. Seiring dengan meningkatnya minat dan permintaan masyarakat terhadap kopi, terdapat juga perkembangan dalam jumlah kedai kopi dan coffee shop di Indonesia. Coffee shop tersebut menyediakan fasilitas yang beragam. Penyediaan wi-fi, air conditioner (AC), board game, stopkontak pada berbagai sudut coffee shop, dan musik yang menenangkan adalah beberapa contoh dari fasilitas coffee shop yang diadakan untuk menciptakan suasana yang sesuai dengan keinginan konsumen.

Terjadi pula perkembangan jumlah coffee shop yang dibangun di wilayah sekitar universitas atau sekolah. Coffee shop ini pun menyesuaikan fasilitas yang ditawarkannya sesuai dengan kebutuhan dan keinginan mahasiswa. Selain menyediakan kopi, coffee shop juga menyediakan berbagai makanan dan ditunjang pula dengan fasilitas seperti ruangan yang nyaman untuk mengobrol atau menyelenggarakan rapat dengan anggota tidak terlalu banyak, serta adanya $w i-f i$, stopkontak yang tersedia dalam jumlah banyak, dan suasana yang tenang sehingga cocok bagi mahasiswa untuk bisa mengkonsumsi kopi sambil mengerjakan tugas. Dalam penelitian ini, coffee shop tersebut diklasifikasikan berdasarkan klasifikasi berikut ini.

\begin{tabular}{ll} 
Tabel 1. Klasifikasi Perusahaan \\
\hline PERUSAHAAN & $\begin{array}{l}\text { PERUSAHAAN } \\
\text { BECIL }\end{array}$ \\
\hline $\begin{array}{l}\text { Umumnya dikelola } \\
\text { oleh pemiliknya }\end{array}$ & $\begin{array}{l}\text { Biasanya dikelola bukan } \\
\text { oleh pemiliknya }\end{array}$ \\
\hline $\begin{array}{l}\text { Struktur organisasi } \\
\text { sederhana }\end{array}$ & $\begin{array}{l}\text { Struktur organisasinya } \\
\text { kompleks }\end{array}$ \\
\hline $\begin{array}{l}\text { Hubungan pemilik } \\
\text { dengan karyawan } \\
\text { dekat }\end{array}$ & $\begin{array}{l}\text { Pemilik hanya } \\
\text { mengenal sedikit } \\
\text { karyawan }\end{array}$ \\
\hline $\begin{array}{l}\text { Persentase } \\
\text { kegagalan } \\
\text { perusahaan tinggi }\end{array}$ & $\begin{array}{l}\text { Persentase kegagalan } \\
\text { perusahaan rendah }\end{array}$ \\
\hline $\begin{array}{l}\text { Kurangnya tenaga } \\
\text { manajer yang andal }\end{array}$ & $\begin{array}{l}\text { Banyak manajemen } \\
\text { handal }\end{array}$ \\
\hline $\begin{array}{l}\text { Sulit memperoleh } \\
\text { modal jangka }\end{array}$ & $\begin{array}{l}\text { Modal jangka panjang } \\
\text { biasanya relatif mudah } \\
\text { panjang }\end{array}$ \\
\hline \begin{tabular}{l} 
diperoleh \\
\hline
\end{tabular}
\end{tabular}

Sumber: Fuad, M., Christine H., Nurlela, Sugiarto, Paulus Y.E.F. 2001.

Berdasarkan klasifikasi di atas perusahaan kecil yang menjadi tempat penelitian adalah Banyubiru Coffee \& Co. dan perusahaan besar yang menjadi tempat penelitian adalah Warunk Upnormal.

$$
\text { Mahasiswa yang umumnya }
$$
termasuk ke dalam generasi $\mathrm{Z}$ juga 
memiliki pola pikir dan pola konsumsi yang berbeda. Generasi Z memiliki ekspektasi yang tinggi terhadap makanan bersih dan organic yang diproduksi secara etis dan berkelanjutan. Untuk kopi yang mereka minum, Generasi Z mengharapkan bahwa hal yang dikonsumsi berasal dari sumber yang berkualitas dan tidak berbahaya terhadap lingkungan.

Kecamatan Jatinangor, Kabupaten Sumedang, Provinsi Jawa Barat merupakan sebuah kecamatan yang di dalamnya terdapat empat perguruan tinggi yaitu Universitas Padjadjaran (Unpad), Institut Teknologi Bandung (ITB), Institut Koperasi Indonesia (Ikopin), dan Institut Pemerintahan Dalam Negeri (IPDN). Mahasiswa-mahasiswa yang terdaftar di perguruan tinggi tersebut menghabiskan banyak waktunya di Kecamatan Jatinangor dan di antaranya menjadi penghuni sementara Kecamatan Jatinangor. Kawasan Jatinangor menjadi lingkungan pendidikan dengan banyaknya jumlah mahasiswa.

Dalam beberapa tahun terakhir ini juga bermunculan beberapa coffee shop di lingkungan Jatinangor. Maraknya perkembangan coffee shop akhir-akhir ini juga melahirkan tuntutan bagi masingmasing coffee shop untuk memiliki strategi pemasaran yang baik. Untuk itu perusahaan perlu mengetahui karakteristik profil konsumen dan bagaimana preferensi konsumen khususnya bagi konsumen Generasi Z yang merupakan generasi muda dan akan menjadi generasi penerus bangsa dalam beberapa tahun ke depan. Karena hal-hal tersebut di atas maka diperlukan analisa mengenai segmentasi konsumen kopi Generasi Z pada coffee shop-coffee shop yang ada di lingkungan kampus Jatinangor. Tujuan dari penelitian ini adalah mengidentifikasi segmentasi berdasarkan karakteristik demografi dan psikografi konsumen generasi $\mathrm{Z}$ di lingkungan Jatinangor dan mengidentifikasi perbedaan karakteristik dan segmentasi konsumen generasi $\mathrm{Z}$ di lingkungan Jatinangor.

\section{METODE PENELITIAN}

Tempat penelitian adalah dua coffee shop yang terletak di lingkungan kampus Jatinangor yaitu Warunk Upnormal dan Banyubiru Coffee \& Co. Pemilihan tempat penelitian di dua coffee shop di Jatinangor dilakukan secara purposive (sengaja). Penelitian ini menggunakan pendekatan kuantitatif. Metode yang digunakan dalam penelitian ini adalah metode survey. Metode pengambilan sampel dalam penelitian ini menggunakan 
metode systematic random sampling yaitu pengambilan sampel dengan selang interval waktu 15 menit dan didapatkan hasil sebesar 75 responden pada coffee shop kecil dan 88 responden pada coffee shop besar.

Variabel yang diteliti dalam penelitian ini adalah:

1. Karakteristik demografi yaitu jenis kelamin, usia, pendapatan/uang saku per bulan, pekerjaan, jarak coffee shop dengan tempat tinggal, dan waktu tempuh menuju coffee shop.

2. Karakter psikografis yaitu aktivitas (activities), minat (interest), dan pendapat (opinion).

Rancangan analisis data yang digunakan dalam penelitian ini adalah analisis deskriptif dan analisis diskriminan.

\section{HASIL DAN PEMBAHASAN}

\section{Karakteristik Demografi Konsumen}

Jenis kelamin konsumen generasi Z pada kedua coffee shop didominasi oleh perempuan. Meskipun begitu, tidak terdapat selisih besar di antara jumlah konsumen laki-laki dan perempuan. Pada coffee shop kecil perbandingan laki-laki terhadap perempuan sedikit lebih kecil dibandingkan pada coffee shop besar. Hasil ini berbeda dengan hasil penelitian
Demura et al. (2013) mengenai perbedaan gender konsumen kopi yang dilaksanakan di Jepang dengan hasil penelitian lebih banyak responden laki-laki mengkonsumsi kopi dengan persentase konsumsi kopi sebesar 50,8\% dibandingkan perempuan.

Berdasarkan usia, konsumen coffee shop generasi Z di kedua coffee shop didominasi oleh kelompok usia $21-23$ tahun dan disusul oleh kelompok usia 18 20 tahun. Dua kelompok umur di atas selaras dengan umur mayoritas mahasiswa universitas.

Pendapatan atau uang saku konsumen generasi $\mathrm{Z}$ di kedua coffee shop didominasi oleh konsumen berpendapatan dalam kisaran $\mathrm{Rp} 1.000 .000-\mathrm{Rp}$ 3.000.000.

Konsumen generasi $\mathrm{Z}$ pada kedua coffee shop didominasi oleh konsumen berprofesi pelajar atau mahasiswa. Hal ini berkaitan dengan generasi $Z$ yang mayoritas berada di usia sekolah dan kuliah. Selain itu, Kecamatan Jatinangor merupakan wilayah pendidikan tempat di mana banyak mahasiswa beraktivitas.

Konsumen generasi $\mathrm{Z}$ pada kedua coffee shop didominasi oleh konsumen dengan jarak coffee shop dengan tempat tinggal sejauh $1 \mathrm{~km}-15 \mathrm{~km}$. Berkaitan dengan itu, konsumen generasi $\mathrm{Z}$ pada 
kedua coffee shop didominasi oleh konsumen dengan waktu tempuh dari tempat tinggal ke coffee shop dalam waktu $1-20$ menit.

Tabel 2 . Segmentasi Demografi Konsumen

\begin{tabular}{|c|c|c|c|c|c|}
\hline \multirow[b]{2}{*}{ Segmentasi Demografi } & \multicolumn{4}{|c|}{ Jumlah Responden } & \multirow{2}{*}{$\begin{array}{c}\text { Total } \\
\text { Responden }\end{array}$} \\
\hline & $\begin{array}{c}\text { Coffee Shop } \\
\text { Besar } \\
\end{array}$ & Persentase & $\begin{array}{c}\text { Coffee Shop } \\
\text { Kecil } \\
\end{array}$ & Persentase & \\
\hline \multicolumn{6}{|l|}{ Jenis Kelamin } \\
\hline Laki-laki & 33 & $20,25 \%$ & 30 & $18,40 \%$ & 63 \\
\hline Perempuan & 55 & $33,74 \%$ & 45 & $27,61 \%$ & 100 \\
\hline \multicolumn{6}{|l|}{ Kelompok Usia } \\
\hline$>15$ & - & $0 \%$ & - & $0 \%$ & - \\
\hline $15-17$ & 14 & $8,59 \%$ & - & $0 \%$ & 14 \\
\hline $18-20$ & 29 & $17,79 \%$ & 22 & $13,50 \%$ & 51 \\
\hline $21-23$ & 45 & $27,61 \%$ & 53 & $32,51 \%$ & 98 \\
\hline \multicolumn{6}{|c|}{ Pendapatan/Uang Saku per Bulan } \\
\hline$>1.000 .000$ & 30 & $18,40 \%$ & 17 & $10,43 \%$ & 47 \\
\hline $1.000 .000-3.000 .000$ & 51 & $31,29 \%$ & 55 & $33,74 \%$ & 106 \\
\hline$>3.000 .000$ & 7 & $4,30 \%$ & 3 & $1,84 \%$ & 10 \\
\hline \multicolumn{6}{|l|}{ Pekerjaan } \\
\hline Pelajar/Mahasiswa & 73 & $44,78 \%$ & 67 & $41,10 \%$ & 140 \\
\hline Karyawan Swasta & 11 & $6,75 \%$ & 2 & $1,23 \%$ & 13 \\
\hline PNS & - & $0 \%$ & - & $0 \%$ & - \\
\hline Lainnya & 4 & $2,46 \%$ & 6 & $3,68 \%$ & 10 \\
\hline \multicolumn{6}{|l|}{ Jarak (dalam km) } \\
\hline $1-15$ & 73 & $44,79 \%$ & 73 & $44,78 \%$ & 146 \\
\hline $16-30$ & 15 & $9,20 \%$ & 2 & $1,23 \%$ & 17 \\
\hline $31-46$ & - & $0 \%$ & - & $0 \%$ & - \\
\hline$>46$ & - & $0 \%$ & - & $0 \%$ & - \\
\hline \multicolumn{6}{|c|}{ Waktu tempuh (dalam menit) } \\
\hline $1-20$ & 57 & $34,97 \%$ & 64 & $39,26 \%$ & 121 \\
\hline $21-40$ & 22 & $13,50 \%$ & 11 & $6,75 \%$ & 33 \\
\hline $41-60$ & 8 & $4,91 \%$ & - & $0 \%$ & 8 \\
\hline$>60$ & 1 & $0,61 \%$ & - & $0 \%$ & 1 \\
\hline Jumlah & 88 & $53,99 \%$ & 75 & $46,01 \%$ & 163 \\
\hline
\end{tabular}

Sumber: Analisis Data Primer (2019)

\section{Segmentasi Psikografi Konsumen}

\section{Coffee Shop}

Mayoritas konsumen generasi $\mathrm{Z}$ pada kedua coffee shop menjawab bahwa mereka mencari informasi tentang kopi.

Mayoritas konsumen generasi Z pada kedua coffee shop memiliki intensitas meminum kopi dalam satu minggu sebanyak 1 kali dan di posisi kedua dengan selisih yang sedikit yaitu $2-4$ kali. Responden pada coffee shop kecil memiliki jumlah yang sama pada kelompok intensitas 1 kali dan intensitas 2 - 4 kali. Pada coffee shop besar tidak ada responden yang meminum kopi dengan intensitas $>7$ kali per minggu dan responden dengan intensitas 5 - 7 kali juga lebih rendah dibandingkan coffee shop kecil.

Mayoritas konsumen generasi $\mathrm{Z}$ pada kedua coffee shop meminum kopi pada waktu malam hari dan di posisi 
kedua yaitu pada sore hari. Pada coffee shop besar persentase tertinggi adalah konsumen meminum kopi pada sore hari sementara pada coffee shop kecil persentase tertinggi adalah konsumen yang meminum kopi pada malam hari.

Tabel 3. Segmentasi Psikografi Konsumen Berdasarkan Aktivitas (Activities)

\begin{tabular}{|c|c|c|c|c|}
\hline \multirow[b]{2}{*}{$\begin{array}{l}\text { Psikografi } \\
\text { Konsumen }\end{array}$} & \multicolumn{4}{|c|}{ Jumlah Responden } \\
\hline & \multicolumn{2}{|c|}{$\begin{array}{l}\text { Coffee Shop } \\
\text { Besar }\end{array}$} & \multicolumn{2}{|c|}{$\begin{array}{l}\text { Coffee Shop } \\
\text { Kecil }\end{array}$} \\
\hline \multicolumn{5}{|c|}{ Mencari informasi tentang kopi } \\
\hline $\mathrm{Ya}$ & 61 & $37,42 \%$ & 57 & $34,97 \%$ \\
\hline Tidak & 27 & $16,57 \%$ & 18 & $11,04 \%$ \\
\hline \multicolumn{5}{|c|}{ Intensitas meminum kopi per minggu } \\
\hline 1 & 45 & $27,61 \%$ & 29 & $17,79 \%$ \\
\hline $2-4$ & 38 & $23,31 \%$ & 29 & $17,79 \%$ \\
\hline $5-7$ & 5 & $3,07 \%$ & 10 & $6,14 \%$ \\
\hline$>7$ & - & $0 \%$ & 7 & $4,29 \%$ \\
\hline \multicolumn{5}{|c|}{ Waktu meminum kopi } \\
\hline Pagi & 4 & $2,45 \%$ & 7 & $4,30 \%$ \\
\hline Siang & 9 & $5,52 \%$ & 7 & $4,30 \%$ \\
\hline Sore & 39 & $23,93 \%$ & 24 & $14,73 \%$ \\
\hline Malam & 36 & $22,09 \%$ & 37 & $22,68 \%$ \\
\hline \multicolumn{5}{|c|}{ Waktu berkunjung ke coffee shop } \\
\hline $1-20$ & 2 & $1,23 \%$ & - & $0 \%$ \\
\hline $21-40$ & 3 & $1,84 \%$ & - & $0 \%$ \\
\hline $41-60$ & 32 & $19,63 \%$ & 15 & $9,20 \%$ \\
\hline$>60$ & 51 & $31,29 \%$ & 60 & $36,81 \%$ \\
\hline \multicolumn{5}{|c|}{ Jam berkunjung ke coffee shop } \\
\hline $10.00-13.00$ & 2 & $1,22 \%$ & - & $0 \%$ \\
\hline $13.01-16.00$ & 21 & $12,88 \%$ & 3 & $1,84 \%$ \\
\hline $16.01-19.00$ & 43 & $26,39 \%$ & 29 & $17,79 \%$ \\
\hline $19.01-22.00$ & 22 & $13,50 \%$ & 43 & $26,38 \%$ \\
\hline \multicolumn{5}{|c|}{$\begin{array}{l}\text { Frekuensi berkunjung ke coffee shop per } \\
\text { minggu }\end{array}$} \\
\hline $1-2$ & 69 & $42,33 \%$ & 48 & $29,45 \%$ \\
\hline $3-4$ & 19 & $11,66 \%$ & 10 & $6,13 \%$ \\
\hline $5-7$ & - & $0 \%$ & 17 & $10,43 \%$ \\
\hline Jumlah & 88 & $53,99 \%$ & 75 & $46,01 \%$ \\
\hline
\end{tabular}

Sumber: Analisis Data Primer (2019)

Mayoritas konsumen generasi $\mathrm{Z}$ di kedua coffee shop menghabiskan waktu lebih dari 60 menit di dalam coffee shop. Hal ini berarti konsumen pada umumnya menghabiskan waktu lebih dari satu jam di coffee shop untuk minum, makan, bersosialisasi, atau mengerjakan tugas. Tidak ada responden yang memilih waktu berkunjung 1 - 20 menit dan 21-40 menit di coffee shop kecil, sementara pada coffee shop besar ada namun dalam jumlah yang sedikit.

Mayoritas konsumen generasi $\mathrm{Z}$ pada kedua coffee shop memilih waktu berkunjung pada jam 16.01 - 19.00 dengan persentase sebesar $44,18 \%$ lalu diikuti oleh jam 19.01 - 22.00 dengan persentase sebesar 39,88\%. Hal ini berkaitan dengan konsumen yang mayoritas merupakan mahasiswa yang memiliki jam selesai kuliah pada sore hari. Pada coffee shop besar mayoritas responden memilih jam berkunjung pada pukul 16.01 - 19.00 sementara pada coffee shop kecil mayoritas responden memilih jam berkunjung pada pukul $19.01-22.00$. Jam ramai atau peak hour pada kedua coffee shop pun terletak pada pukul 18.00 - 22.00. Pada coffee shop kecil lebih banyak responden yang memilih waktu yang lebih larut dibandingkan pada coffee shop besar.

Mayoritas konsumen generasi $\mathrm{Z}$ di kedua coffee shop memiliki frekuensi berkunjung ke coffee shop sebesar $1-2$ kali per minggu. Pada coffee shop besar tidak ada responden yang berkunjung 
dalam frekuensi $5-7$ kali per minggu. Dapat dilihat bahwa pada coffee shop kecil terdapat konsumen yang datang setiap hari.

Tabel 4. Segmentasi Psikografi Konsumen Berdasarkan Minat (Interest)

\begin{tabular}{c|c|c|c|c}
\hline \multirow{2}{*}{$\begin{array}{c}\text { Psikografi } \\
\text { Konsumen }\end{array}$} & \multicolumn{3}{c}{$\begin{array}{c}\text { Coffee Shop } \\
\text { Besar }\end{array}$} & \multicolumn{3}{c}{$\begin{array}{c}\text { Coffee Shop } \\
\text { Kecil }\end{array}$} \\
\hline Metode penyeduhan kopi yang disukai \\
\hline $\begin{array}{c}\text { Espresso } \\
\text { based }\end{array}$ & 57 & $34,97 \%$ & 43 & $26,38 \%$ \\
\hline $\begin{array}{c}\text { Manual } \\
\text { brew }\end{array}$ & 31 & $19,02 \%$ & 32 & $19,63 \%$ \\
\hline Tipe peminum kopi \\
\hline $\begin{array}{c}\text { Pecandu } \\
\text { kafein }\end{array}$ & 4 & $2,46 \%$ & 21 & $12,88 \%$ \\
\hline $\begin{array}{c}\text { Pemburu } \\
\text { latte art }\end{array}$ & 15 & $9,20 \%$ & 10 & $6,14 \%$ \\
\hline $\begin{array}{c}\text { Frappuccino } \\
\text { fanatic }\end{array}$ & 11 & $6,75 \%$ & 7 & $4,29 \%$ \\
\hline $\begin{array}{c}\text { Penyuka } \\
\text { teknik }\end{array}$ & 6 & $3,68 \%$ & 7 & $4,29 \%$ \\
manual brew & 52 & $31,90 \%$ & 30 & $18,41 \%$ \\
\hline $\begin{array}{c}\text { Social } \\
\text { drinker }\end{array}$ & 5
\end{tabular}

Biaya yang dikeluarkan sekali berkunjung ke coffee shop

\begin{tabular}{c|c|c|c|c}
\hline$<50.000$ & 67 & $41,11 \%$ & 71 & $43,56 \%$ \\
\hline $\begin{array}{c}50.000- \\
100.000\end{array}$ & 21 & $12,88 \%$ & 4 & $2,45 \%$ \\
\hline$>100.000$ & - & $0 \%$ & - & $0 \%$ \\
\hline Orang yang berkunjung dengan konsumen \\
\hline Sendiri & 6 & $36,8 \%$ & 17 & $10,43 \%$ \\
\hline $\begin{array}{c}\text { Teman/Pasa } \\
\text { ngan }\end{array}$ & 76 & $46,63 \%$ & 57 & $34,97 \%$ \\
\hline Keluarga & 6 & $3,68 \%$ & - & $0 \%$ \\
\hline Rekan & - & $0 \%$ & 1 & $0,61 \%$ \\
\hline
\end{tabular}

Jumlah kelompok orang yang berkunjung dengan konsumen

\begin{tabular}{c|c|c|c|c}
\hline $1-2$ & 36 & $22,09 \%$ & 14 & $8,59 \%$ \\
\hline $3-4$ & 40 & $24,54 \%$ & 40 & $24,54 \%$ \\
\hline $5-6$ & 9 & $5,52 \%$ & 17 & $10,43 \%$ \\
\hline$>7$ & 3 & $1,84 \%$ & 4 & $2,45 \%$ \\
\hline Jumlah & 88 & $53,99 \%$ & 75 & $46,01 \%$ \\
\hline
\end{tabular}

Sumber: Analisis Data Primer (2019)

Mayoritas konsumen generasi $\mathrm{Z}$ pada kedua coffee shop memilih metode espresso based. Espresso dihasilkan dengan cara mengekstraksi kopi dengan menyemburkan air panas di bawah tekanan tinggi ke biji kopi yang sudah digiling. Sementara teknik manual brew adalah cara penyeduhan kopi manual dengan tangan manusia dan air.

Mayoritas konsumen generasi $\mathrm{Z}$ di kedua coffee shop mengidentifikasi diri mereka sendiri sebagai tipe social drinker. Pada coffee shop kecil tipe pecandu kafein memiliki persentase terbanyak kedua sementara pada coffee shop besar tipe pecandu kafein memiliki jumlah yang paling sedikit. Hal ini juga berkaitan dengan frekuensi berkunjung yang ratarata nya lebih tinggi pada coffee shop kecil.

Mayoritas konsumen generasi $\mathrm{Z}$ di kedua coffee shop mengeluarkan biaya sebesar kurang dari Rp50.000,- dalam sekali berkunjung ke coffee shop. Hal ini berkaitan dengan harga menu minuman kopi di kedua coffee shop yang semuanya di bawah Rp50.000,-.

Mayoritas konsumen generasi $\mathrm{Z}$ di kedua coffee shop umumnya datang ke coffee shop bersama teman atau pasangan mereka. Hal ini selaras dengan konsep kedua coffee shop yang menyediakan workspace sekaligus tempat bersosialisasi di mana konsumen dapat mengerjakan tugas sekaligus bersosialisasi dengan teman atau pasangan. Mayoritas 
konsumen juga merupakan mahasiswa yang tidak tinggal bersama keluarga sehingga lebih banyak menghabiskan waktunya bersama teman atau pasangan.

Mayoritas konsumen generasi $\mathrm{Z}$ di kedua coffee shop datang dalam jumlah orang $3-4$ orang. Di posisi kedua dengan selisih yang tidak terlalu besar mayoritas responden datang ke coffee shop dalam jumlah $1-2$ orang. Hal ini berarti kebanyakan konsumen berkunjung ke coffee shop dalam kelompok yang cukup besar.

Tabel 5. Segmentasi Psikografi Konsumen Berdasarkan Pendapat (Opinion)

\begin{tabular}{|c|c|c|c|c|}
\hline \multirow[b]{2}{*}{$\begin{array}{l}\text { Psikografi } \\
\text { Konsumen }\end{array}$} & \multicolumn{4}{|c|}{ Jumlah Responden } \\
\hline & \multicolumn{2}{|c|}{$\begin{array}{c}\text { Coffee Shop } \\
\text { Besar }\end{array}$} & \multicolumn{2}{|c|}{$\begin{array}{c}\text { Coffee Shop } \\
\text { Kecil }\end{array}$} \\
\hline \multicolumn{5}{|c|}{ Niat untuk berkunjung kembali } \\
\hline $\mathrm{Ya}$ & 88 & $53,99 \%$ & 75 & $46,01 \%$ \\
\hline Tidak & - & $0 \%$ & - & $0 \%$ \\
\hline \multicolumn{5}{|c|}{ Alasan berkunjung ke coffee shop } \\
\hline $\begin{array}{l}\text { Atmosfer/Suas } \\
\text { ana }\end{array}$ & 38 & $23,31 \%$ & 36 & $22,09 \%$ \\
\hline $\begin{array}{c}\text { Layanan } \\
\text { pramusaji }\end{array}$ & 1 & $0,61 \%$ & 4 & $2,45 \%$ \\
\hline Produk & 27 & $16,56 \%$ & 14 & $8,59 \%$ \\
\hline $\begin{array}{c}\text { Penilaian } \\
\text { coffee shop }\end{array}$ & 1 & $0,61 \%$ & 4 & $2,45 \%$ \\
\hline Lokasi & 8 & $4,92 \%$ & 7 & $4,29 \%$ \\
\hline Fasilitas & 13 & $7,98 \%$ & 10 & $6,14 \%$ \\
\hline Jumlah & 88 & $53,99 \%$ & 75 & $46,01 \%$ \\
\hline
\end{tabular}

Sumber: Analisis Data Primer (2019)

Seluruh konsumen generasi $\mathrm{Z}$ di kedua coffee shop sebanyak 100\% memiliki keputusan untuk berkunjung kembali.

Mayoritas konsumen generasi $\mathrm{Z}$ di kedua coffee shop datang dengan alasan berkunjung berupa atmosfer atau suasana coffee shop dengan persentase sebesar $45,30 \%$. Hal ini sesuai dengan konsep utama kedua coffee shop yang menyediakan suasana nyaman dan tenang dari penggunaan fasilitas dan dekorasi coffee shop.

\section{Analisis Diskriminan}

Variabel usia, intensitas, biaya, ratarata kunjungan, jumlah orang, jarak, waktu tempuh, waktu di coffee shop, dan jam berkunjung dapat digunakan untuk mengidentifikasi perbedaan antar kategori.

Tabel 6. Variables Entered

\begin{tabular}{clc}
\hline Step & \multicolumn{1}{c}{ Entered } & Sig. \\
\hline 1 & Jam berkunjung & .000 \\
2 & Waktu tempuh & .000 \\
3 & Intensitas minum kopi & .000 \\
4 & Usia & .000 \\
5 & Biaya & .000 \\
6 & Jumlah Orang & .000 \\
\hline
\end{tabular}

Berdasarkan tabel di atas, terdapat variabel yang dimasukkan dalam tiap tahap. Terdapat 6 tahapan sehingga terdapat 6 variabel yang masuk model. Variabel yang masuk model adalah variabel yang mempunyai pengaruh signifikan dan dapat dilanjutkan untuk analisis diskriminan yaitu variabel jam berkunjung, waktu tempuh, intensitas minum kopi, usia, biaya, dan jumlah orang. 
Tabel 7. Structure Matrix

\begin{tabular}{l|l}
\hline \multicolumn{2}{c}{ Structure Matrix } \\
\hline & Function \\
\hline Jam berkunjung & .563 \\
Rata-rata kunjungan & .415 \\
Usia & .380 \\
Biaya & -.371 \\
Waktu tempuh & -.364 \\
Intensitas & .340 \\
Jumlah orang & .304 \\
\hline
\end{tabular}

Berdasarkan tabel di atas dapat dilihat bahwa korelasi tertinggi antara konsumen pada coffee shop besar dan coffee shop kecil terdapat pada variabel jam kunjungan dengan persentase sebesar $56,3 \%$. Dapat diambil kesimpulan bahwa variabel jam kunjungan memiliki hubungan dengan pemilihan konsumen dalam mengunjungi coffee shop besar atau coffee shop kecil.

Tabel 8. Classification Result

\begin{tabular}{|c|c|c|c|c|c|}
\hline & \multicolumn{3}{|c|}{$\begin{array}{l}\text { Predicted } \\
\text { Group } \\
\text { Member- } \\
\text { ship }\end{array}$} & \multirow[t]{2}{*}{$\begin{array}{l}\text { To- } \\
\text { tal }\end{array}$} \\
\hline & & & B & $\mathbf{K}$ & \\
\hline \multirow{4}{*}{$\begin{array}{l}\text { Ori- } \\
\text { ginal }\end{array}$} & Count & B & 57 & 29 & 86 \\
\hline & & K & 16 & 59 & 75 \\
\hline & $\%$ & B & 66,3 & 33,7 & 100 \\
\hline & & K & 21,3 & 78,7 & 100 \\
\hline
\end{tabular}

Berdasarkan tabel di atas dapat dilihat klasifikasi antara konsumen pada coffee shop besar dan coffee shop kecil. Hasil ini dapat digunakan untuk melihat seberapa besar kecocokan antara prediksi SPSS dengan original. Hasil tersebut didapat dari:
1. Jumlah coffee shop besar original dan coffee shop besar predicted $=57$

2. Jumlah coffee shop kecil original dan coffee shop kecil predicted $=59$

Kemudian diklasifikasikan dengan cara

$$
\begin{aligned}
& =\frac{57+59}{\text { Total Responden }} \times 100 \% \\
& =\frac{116}{163} \times 100 \% \\
& =71,16 \%
\end{aligned}
$$

Maka hasil dari kecocokan antara prediksi SPSS dengan original adalah $71,16 \%$.

Berdasarkan analisis diskriminan terdapat enam variabel yang mendominasi konsumen dalam mengunjungi coffee shop besar dan coffee shop kecil dan memiliki pengaruh signifikan. Variabel pertama adalah jam kunjungan. Pada coffee shop besar mayoritas responden memilih waktu berkunjung pada pukul 16.01-19.00 sementara pada coffee shop kecil mayoritas responden memilih waktu berkunjung pada pukul 19.01-22.00. Variabel kedua adalah waktu tempuh. Variabel ketiga adalah intensitas minum kopi per minggu di mana responden dari coffee shop besar memiliki intensitas 
minum kopi yang lebih sedikit dibandingkan dengan responden dari coffee shop kecil. Variabel keempat adalah usia. Rata-rata usia lebih rendah pada coffee shop besar dan lebih tua pada coffee shop kecil. Variabel kelima adalah biaya yang dikeluarkan dalam sekali berkunjung ke coffee shop. Variabel keenam adalah jumlah orang kelompok konsumen berkunjung ke coffee shop. Variabel yang tidak memiliki perbedaan signifikan di antara dua kategori coffee shop adalah variabel pendapatan/uang saku per bulan, intensitas kunjungan per minggu, jarak, dan jumlah waktu yang dihabiskan di coffee shop.

\section{KESIMPULAN DAN SARAN}

Perbedaan konsumen coffee shop besar dan coffee shop kecil yang dianalisis menggunakan alat analisis diskriminan terdapat pada variabel usia, intensitas, biaya, rata-rata kunjungan, jumlah orang, jarak, waktu tempuh, waktu di coffee shop, dan jam berkunjung. Sementara itu tidak terdapat perbedaan yang signifikan pada variabel pendapatan. Korelasi tertinggi antara konsumen pada coffee shop besar dan coffee shop kecil terdapat pada variabel jam kunjungan. Sementara variabel yang memiliki pengaruh signifikan adalah variabel jam kunjungan, waktu tempuh, intensitas minum kopi per minggu, usia, biaya yang dikeluarkan, dan jumlah kelompok orang.

Saran bagi Warunk Upnormal sebaiknya menyesuaikan strategi sesuai dengan karakteristik dan preferensi mayoritas konsumen generasi $\mathrm{Z}$ yaitu memberikan promosi yang menarik bagi mahasiswa, memperbanyak menu kopi espresso based, dan mempertahankan atmosfer dan suasana agar nyaman untuk konsumen berdiam dalam waktu cukup lama dan untuk bersosialisasi. Atribut coffee shop yang dianggap sangat penting dapat dipertahankan dan dikembangkan lebih baik lagi yaitu untuk kenyamanan dan kebersihan, fasilitas free wi-fi, pelayanan, layanan terhadap keluhan, dan rasa kopi yang unik.

Saran bagi Banyubiru Coffee \& Co. sebaiknya menyesuaikan strategi sesuai dengan karakteristik mayoritas konsumen generasi $\mathrm{Z}$ yaitu memberikan promosi yang menarik bagi mahasiswa, meningkatkan suasana pada saat malam hari, menyediakan suasana yang nyaman bagi konsumen yang berdiam dalam waktu cukup lama, dan menambah menu espresso based. Atribut yang dianggap sangat penting dapat dipertahankan dan dikembangkan lebih baik lagi yaitu kenyamanan dan kebersihan, fasilitas free 
$w i-f i$, fasilitas pendingin ruangan, penilaian atau review yang baik, pelayanan, penguasaan informasi oleh karyawan, serta rasa kopi yang unik

\section{DAFTAR PUSTAKA}

Demura, S., Aoki, H., Mizusawa, T., Soukura, K., Noda, M., \& Sato, T. (2013). Gender Differences in Coffee Consumption and Its Effects in Young People. Food and Nutrition Sciences, 04(07), 748757.

https://doi.org/10.4236/fns.2013.47

096
Koo, D. M. (2003). Inter-relationships among store images, store satisfaction, and store loyalty among Korea discount retail patrons. In Asia Pacific Journal of Marketing and Logistics (Vol. 15). https://doi.org/10.1108/1355585031 0765033

Leha, J. M., \& Subagio, D. H. (2014). Pengaruh Atribut Cafe Terhadap Motif Belanja Hedonik Motif Belanja Utulitarian Dan Loyalitas Pelanggan Starbucks Coffee di The Square Apartement Surabaya. Jurnal Manajemen Pemasaran Petra, 2(1), 1-12. Retrieved from http://webmail.jrdelisle.com/JSCR/ 2005Articles/JSCRV13_1A3Shop Motivations.pdf 